Cita: Prado Aragonés, Josefina (2006): "Algunos usos lingüísticos discriminatorios en la última edición del DRAE y la transmisión de valores", en Mar Campos Souto e Ignacio Pérez Pascual, eds., El diccionario de la Real Academia Española: ayer y hoy, A Coruña, Universidade da Coruña, Anexos de Revista de Lexicografía, 1, pp. 199-210. https://doi.org/10.17979/spudc.9788497497466.199

\title{
Algunos usos lingüísticos discriminatorios en la última edición del DRAE y la transmisión de valores
}

\author{
Josefina PRADO ARAGONÉS \\ Universidad de Huelva
}

(cc) BY-NC-SA

La lengua es el instrumento de comunicación y relación entre los miembros de una comunidad y el medio a través del cual éstos conocen, denominan la realidad circundante y conforman su percepción del mundo; de manera que los hablantes, cuando adquirimos nuestra lengua, no sólo adquirimos las palabras que constituyen su léxico y las reglas para combinarlas de forma adecuada en los actos de habla, sino también sus significados y a través de ellos aprehendemos el imaginario común y la experiencia vital de nuestra comunidad, que constituye, en definitiva, nuestra cultura.

A través del conocimiento de las palabras, por tanto, los hablantes recibimos y compartimos un bagaje cultural comunitario, fraguado a través del paso del tiempo, arraigado en la conciencia común y heredado de generación en generación. Este acervo cultural está constituido por patrones y estereotipos sociales, con frecuencia no exentos de prejuicios, que nos sirven para aprender fórmulas de comunicación y relación, conformar y estructurar nuestro pensamiento y modelar nuestro sistema de valores.

Así, gracias a las palabras, entendemos, comprendemos e interpretamos la realidad desde la perspectiva, a menudo sesgada, de quienes nos precedieron en el uso de esas palabras en otras épocas y delimitaron su sentido, pues, como reconoce Calero, en el vocabulario «se contiene el mundo conocido y pensado por los hablantes y del modo en que dicho mundo ha sido conocido y pensado, siempre desde una óptica particular y reductora» (1999: 151).

El léxico y las palabras que lo constituyen, que es el nivel más indefinido e inestable de la lengua y el que mejor refleja los cambios sociales y culturales, es recogido en las páginas de los diccionarios y en ellas se institucionaliza y adquiere rango de norma ya que, en palabras de Calero, «si la lengua impone una imagen del mundo, el diccionario la sanciona al dar valor social al léxico que expone entre sus 
páginas y a los significados que recoge» (1999: 155). De esta forma, las obras lexicográficas se convierten en instrumentos didácticos y discursos pedagógicos (Dubois 1971, Rey-Debove 1997, Alvar Ezquerra 1981), con un evidente valor formativo no sólo lingüístico, sino también social, cuya importancia, en palabras de Alvar Ezquerra, «trasciende los límites puramente lingüísticos o culturales, hasta el punto de poder influir de una manera decisiva sobre el desarrollo de la sociedad» (1993: 23), pues enseña a quienes los consultan saberes lingüísticos, pero también culturales e ideológicos (Forgas 1996, Pascual y Olaguíbel 1992) y establece socialmente modelos léxicos de uso desde el momento en que, como apunta Lara, «orienta la memoria del léxico cultivado, seleccionando su composición, restringiendo sus posibilidades e imponiendo una concepción de la lengua histórica a la comunidad» (1997: 257).

Pero, a veces, la imagen del mundo que el diccionario presenta, no es una imagen auténtica y compartida socialmente, puesto que, como aseguran Pascual y Olaguíbel, «no existe un mundo real objetivo, sino el que corresponde al modelo social dominante» (1992: 73-74); por el contrario, a menudo se trata de una imagen deformada, impuesta en función de determinados intereses, pero legitimada desde el momento en que aparece plasmada en las páginas del diccionario, que transmite y contribuye a perpetuar determinados estereotipos discriminatorios, originados en épocas pretéritas, la mayoría de los cuales están superados en la actualidad como consecuencia de la lógica evolución social, como ocurre con algunos términos que, en nuestra opinión, entrañan sexismo, recogidos en las páginas del Diccionario de la lengua española, de la Real Academia (DRAE), en su vigésima segunda edición de 2001.

Como se manifiesta en las advertencias para el uso de este diccionario académico, normativo y modélico por excelencia, en él se pretende recoger «el léxico general de la lengua hablada en España y en los países hispánicos», y, ya que este tipo de diccionario no puede abarcar todo el léxico español, se especifica que «por fuerza, debe contentarse con acoger una selección de nuestro código verbal», aclarándose a continuación que «esta selección, en algunos casos será la más completa que los medios a nuestro alcance permitan -especialmente en lo que se refiere al léxico de la lengua culta y común de nuestros días-, mientras que en otros aspectos [...]», refiriéndose a diversas marcas de uso, «se limitará a incorporar una representación de los usos más extendidos o característicos» (DRAE-2001: xxxIII). Pese a estas advertencias preliminares, la realidad de la selección de su corpus es otra bien distinta, pues, como es sabido, este diccionario viene arrastrando en sus sucesivas ediciones lastres culturales de épocas pasadas, heredados de sus fuentes, bajo el pretexto, como reza también en las advertencias para su uso, de que «el repertorio académico, en tanto no se haya completado la redacción del Diccionario histórico, debe seguir albergando una selección del léxico hispano cronológicamente desfasado, que permita interpretar al lector los textos clásicos de nuestra lengua» (DRAE-2001: XxxIII), a pesar de que su uso social haya desaparecido o sea muy poco frecuente $y$, por tanto, no corresponda a 
la realidad lingüística actual. Así, en sus páginas se siguen manteniendo muchas entradas anticuadas ya en franco desuso, algunas definidas mediante un discurso anacrónico y tendencioso, lejos de la actualidad y objetividad que sería deseable en esta obra lexicográfica, modelo de referencia ineludible en el mundo hispánico, que transmiten una visión del mundo trasnochada, cargada de convencionalismos y prejuicios heredados de épocas pretéritas que nada o muy poco tienen que ver con las transformaciones sociales del mundo actual y que pueden inducir a pensar a quienes consulten sus páginas que las mismas gozan de plena vigencia y reconocimiento social, puesto que aparecen allí recogidas y la mayoría carece de marca de cronología o de uso que afirmen lo contrario, como anticuado, desusado o poco usado.

Analizamos a continuación algunos de esos usos léxicos discriminatorios que siguen estando presentes en las páginas del diccionario académico, pese a las transformaciones sociales que exigen su revisión y adecuación a la realidad del momento. Estos términos entrañan sexismo, a nuestro juicio, por dos razones fundamentales:

- En primer lugar, porque muchos de ellos son términos antiguos, de escaso o ningún uso social, que designan realidades superadas en la actualidad y que comportan un trato ofensivo para la mujer, con entradas únicas en femenino y sin correspondencia con otros términos semejantes referidos al hombre; $y$, cuando éstos tienen flexión de género, el masculino recibe muy distinta consideración en su tratamiento lexicográfico. Sin embargo, dichos términos permanecen en el corpus del diccionario académico, pese a que la docta institución reconoce este anacronismo en la introducción a la última edición de este diccionario, y así afirma que «no ha sido fácil, trabajar sobre un diccionario cuyos artículos fueron redactados, en proporción nada desdeñable, hace muchos años, o, en ciertos casos, hace siglos. También ha resultado comprometido proceder con la sospecha -a veces seguridad- de que algunas definiciones no se corresponden con la realidad actual» (DRAE-2001: XXIX).

- Y, en segundo lugar, porque, en nuestra opinión, el discurso lexicográfico con que son definidos esos y otros muchos términos referidos a la mujer es en gran medida tendencioso y subjetivo, y enunciado con una retórica anticuada, cargada de convencionalismos; por ello, necesariamente debe ser revisado sin más dilación, a pesar de la inexcusable prudencia académica a este respecto, reconocida en dicha introducción: «se ha actualizado en lo posible el texto de las definiciones [...]. En este extremo se ha actuado con especial precaución, porque, entre otros aspectos que muestran la singularidad del Diccionario de la Real Academia, la forma de redactar sus artículos es materia que debe ser revisada con gran delicadeza» (DRAE-2001: xxx); en este sentido, y como declaración de buenas intenciones, en dicha intro- 
ducción se nos anuncia que «para un futuro cercano quedan pendientes, entre otras muchas tareas [...], revisar, tomando como base documental el Banco de datos del español, el contenido de todas las definiciones» (DRAE2001: XXXI). Por nuestra parte, esperamos que así sea.

Respecto al tratamiento sexista observado en el diccionario académico, es evidente que las personas somos seres sociales, pero distintos, entre otras cosas por razón de sexo. En el proceso de socialización al que estamos sometidos desde nuestro nacimiento se nos encasilla en un modelo masculino o femenino, según el sexo, constituido por pautas de comportamiento, actitudes y formas lingüísticas que nos definen socialmente y que son producto de una tradición cultural antropocéntrica, en la que el papel de la mujer se ha venido ocultando tradicionalmente de forma sistemática o ha sido desvirtuado mediante connotaciones negativas (García Meseguer 1988, Catalá y García Pascual 1995, Grijelmo 2000). En este sentido, aunque se está avanzando mucho en la detección y erradicación de estereotipos y prejuicios sexistas, aún falta un largo camino por recorrer. De esta forma, y pese a las muchas modificaciones que la última edición del $D R A E$ presenta respecto a la anterior en cuanto a corregir estas desviaciones sexistas, heredadas de tiempos pretéritos, fruto de una tradición social y cultural androcéntrica, aún siguen manteniendose en sus páginas usos léxicos ya anticuados, que suponen un tratamiento discriminatorio para la mujer y que en la sociedad actual ya no tienen sentido.

Para ilustrar este tratamiento lexicográfico obsoleto y discriminatorio, recogemos, como botón de muestra, algunos ejemplos.

Hay en las páginas del $D R A E$ palabras y expresiones que, aunque algunas de ellas socialmente tienen pleno reconocimiento de uso, y, por tanto, el diccionario académico debe recogerlas, en la definición lexicográfica, y eso es lo que nos parece verdadermente llamativo, se presenta una imagen envilecida de la mujer, al mostrarla como un ser lascivo, malicioso y frívolo, cuando no torpe y repugnante. La mayoría de estos términos, curiosamente, no poseen flexión genérica y su lema es siempre femenino; carecen, por tanto, del correspondiente masculino y de otras formas paralelas que se refieran a varón y, si las tiene, no comportan esas mismas connotaciones negativas para el hombre. En las definiciones de los mismos o bien está presente como definidor el término mujer o bien son sustituidas por un sinónimo al que se remite, el cual en su definición lleva presente dicho término. Hemos obviado todos aquellos lemas cuyas definiciones incluyen como definidor el término persona, por entender que, en este caso, el significado designaba indistintamente a hombre y a mujer. Los términos que presentan esta imagen femenina, a nuestro juicio indigna, hacen referencia en su mayoría al mundo animal y son utilizados en sentido metafórico, con las connotaciones de degradación y humillación que ello comporta para la mujer; así, ésta es denominada con algunos nombres de aves, felinos, insectos, arác- 
nidos, para destacar determinados defectos físicos o morales. Algunos de ellos están marcados como uso coloquial («coloq.»), como borrica: «2. f. coloq. Mujer muy necia»; cacatúa: «2. f. coloq. Mujer que pretende disimular en vano los estragos de la ancianidad mediante un exceso de afeites y adornos, y con vestidos ridículamente vistosos»; cuca: «4. f. coloq. Mujer enviciada en el juego»; lechona: «2. f. coloq. Mujer sucia, puerca y desaseada»; pava: «2. f. coloq. Mujer sosa y desgarbada»; pécora: en la expresión mala pécora, «f. coloq. Persona astuta, taimada y viciosa, y más comúnmente siendo mujer». Pero el resto de términos encontrados no tiene ninguna marca de uso y, por tanto, debemos entender que el mismo corresponde al uso general de nuestra lengua, como lechuza: «2. f. Mujer que se asemeja en algo a la lechuza (ave rapaz nocturna)»; tigresa: «2. f. Mujer furiosa, llena de ira»; y «3. f. Mujer seductora, provocadora y activa en las relaciones sexuales»; vampiresa: «f. «Mujer que aprovecha su capacidad de seducción amorosa para lucrarse a costa de aquellos a quienes seduce» y «2. f. mujer fatal»; araña: «6. f. prostituta»; moscona: «f. Mujer desvergonzada».

Otros términos que aluden a seres mitológicos caracterizados por sus comportamientos disolutos o perversos han pasado a designar por antonomasia a ciertas mujeres, estigmatizadas con esas mismas actitudes; bien con la marca coloquial («coloq.»), como arpía: «3. f. colq. Mujer aviesa»; y «4. f. coloq. Mujer muy fea o flaca»; y ninfa: que, si bien en la acepción «2. f. coloq.» significa «Joven hermosa», en la «3. f. coloq.» remite a cortesana («mujer de costumbres libres»); o bien sin marca alguna de uso, como bacante: «2. f. Mujer descocada, ebria y lúbrica»; y ménade: «2. f. Mujer descompuesta y frenética».

Igualmente, están presentes en las páginas del diccionario académico nombres de personajes históricos femeninos célebres por sus malas artes o su vida inmoral que también por antonomasía designan a mujeres a las que se les atribuyen características similares; de esta forma: mesalina: «(por alusión a Mesalina, esposa de Claudio, emperador romano). f. Mujer poderosa y aristocrática y de costumbres disolutas»; anabolena: «(de Ana Bolena, mujer de Enrique VIII, rey de Inglaterra). f. Mujer alocada y trapisondista»; hetera: «f. «En la antigua Grecia, cortesana a veces de elevada consideración social»; y «2. f. prostituta».

Aparecen recogidos, asimismo, algunos nombres femeninos de personajes mitológicos o literarios que han quedado como prototipos de maldad, astucia o grosería, como: circe: «(de Circe, hechicera que en la Odisea convierte a los compañeros de Ulises en bestias). f. Mujer astuta y engañosa»; maritornes «(de Maritornes, personaje del Quijote, de M. de Cervantes, 1547-1616). f. coloq. Moza de servicio, ordinaria, fea y hombruna»; lolita: «(de Lolita, personaje de la novela de W. Navokov, 1899-1977). f. Mujer adolescente, atractiva y seductora».

En las páginas de este diccionario también encontramos términos, a nuestro juicio denigrantes, que hacen especial hincapié en la fealdal y falta de atractivo físico 
de la mujer, sobre todo en su vejez, y en su escaso aseo, y que incluyen otras valoraciones morales negativas asimiladas frecuentemente al físico femenino poco agraciado, las cuales no tienen correspondencia con otros términos referidos al hombre, quizás como claro ejemplo del dicho popular de que «el hombre y el oso cuanto más feo, más hermoso». La mayoría de estos términos aparecen con marcas de registro coloquial («coloq.»), como bruja: «4. f. coloq. Mujer fea y vieja»; callo: «4. m. coloq. Mujer muy fea»; escaldada, con flexión de género, «2. adj. coloq. Dicho de una mujer muy ajada: «Libre y deshonesta en su trato»; pazpuerca: «adj. coloq. Dicho de una mujer: Sucia y grosera»; pendón ${ }^{l}$ : «5. m. coloq. Persona, especialmente mujer, muy alta, desvaída y desaliñada»; tarasca: «3. f. coloq. Mujer temible o denigrada por su agresividad, fealdad, desaseo o excesiva desvergüenza»; otro término doblemente marcado, además de con la marca anterior, con la de poco usado («p. us.»), como carantoña: «4. f. coloq. p. us. Mujer vieja y fea que se aplica y se compone el rostro para disimular su fealdad»; o simplemente con esta última marca, como piltraca: «2. f. p. us. Mujer despreciable»; y, finalmente, otro con marca de regionalismo propio de Andalucía («And.»): chaleco: «5. And. Mujer despreciable y sin atractivos».

También son numerosas las entradas cuyas definiciones hacen referencia a comportamientos morales de la mujer, considerados poco decorosos y honestos, según los convencionalismos sociales más tradicionales y conservadores, incluyendo en las mismas valoraciones subjetivas cargadas de falso puritanismo. Algunas de ellas van marcadas: unas, con registro de uso coloquial («coloq.»), como farota: «f. coloq. Mujer descarada y sin juicio», única acepción recogida; coja: «f. coloq. Mujer de mala vida»; zurrona: «f. coloq. Mujer perdida y estafadora». Otras, además de la marca anterior, también llevan la de despectivo («despect.») o uso como insulto («U. c. insult»), como pingo: «3. m. despect. coloq. Mujer casquivana»; putón: «m. despect. coloq. Mujer de costumbres sexuales muy libres». Y otra, solamente con marca de despectivo, como suripanta: «f. despect. Mujer ruín, moralmente despreciable». Igualmente, hay otras con la marca cronológica de uso antiguo («ant.») o poco uso («p. us.»), como baldonada: «adj. ant. Se decía de la mujer de mala vida»; halconera: con flexión de género, «adj. p. us. Dicho de una mujer y de sus acciones y gestos provocativos: que halconea»; la definición de cuyo infinitivo halconear con marca de poco usado («p. us.») y contorno «intr. p. us. Dicho de una mujer desenvuelta» significa «Dar muestra con su traje, su mirada y movimientos provocativos, de andar a la caza de hombres». Y otra, con marca regional de Andalucía («And.»), corralera, con flexión de género, «5. f. And. Mujer desvergonzada y desenvuelta». Por último, algunas otras no tienen ningún tipo de marca de uso y registro, y, por tanto, se consideran de uso común y actual en nuestra lengua. Su lema se registra morfológicamente bien en masculino, como perico: «7. m. Persona, especialmente mujer, que gusta de callejear $\mathrm{y}$ es a veces de vida desenvuelta»; o flexión de género masculino y femenino, como casquivana, «2. f. Mujer que no tiene formalidad en su trato con el sexo masculino»; 
pendón ${ }^{2}$ : «2. m. y f. Mujer cuyo comportamiento es considerado indecoroso. U. c. insulto»; o bien, sólo entrada femenina, como piruja: «4. f. Mujer joven, libre y desenvuelta»; cualquiera: «2. f. Mujer de mala vida»; prójima: «f. Mujer de poca estimación pública o de dudosa conducta».

Otros términos y expresiones aluden a aquella mujer que incumple el papel social que tradicionalmente se le ha venido asignado, el de ser una mujer discreta y de su casa; esta última expresión es definida en el diccionario académico como «la que con diligencia se ocupa de los quehaceres domésticos y cuida de su hacienda y familia»; por tanto, los siguiente términos y expresiones se refieren a mujeres que sistemáticamente incumplen dichas obligaciones y, en consecuencia, socialmente gozan de mala reputación. Algunos se registran con marca de uso coloquial («coloq.»), como pindonga: «f. coloq. Mujer callejera»; o, en la entrada pingo, las frases andar, estar o ir de pingo alguien: «frs. coloqs.» «Pasar mucho tiempo fuera de casa para divertirse y sin hacer nada de provecho»; o bien, sin marca de uso, como albendera: «2. f. Mujer ociosa, callejera y desaplicada». También tienen el mismo sentido entradas con flexión de género, pero cuya valoración social es muy desigual para el masculino y el femenino. De esta manera: cortesano, na: «5. m. Palaciego que servía al rey en la corte»; mientras que la sexta acepción nos remite a dama cortesana: «6. f. Ramera de calidad»; y la séptima, «7. f. Mujer de costumbres libres».

Igualmente suponen usos sexistas aquéllos que consagran la imagen peyorativa de la mujer, como duales aparentes cuya valoración del femenino es bien diferente del masculino, en expresiones como hombre público, cuyo significado es «m. El que tiene presencia e influjo en la vida social»; frente a mujer perdida o pública, que remite a prostituta; o, en la entrada hijo, las expresiones con marca de uso coloquial: hijo de su madre: «m. y f. coloq. Con alguna viveza para llamar a alguien bastardo o hijo de puta. || 2. m. y f. coloq. Denota la semejanza del hijo con su madre»; frente a hijo de su padre: «m. y f. coloq. Denota la semejanza del hijo en las inclinaciones, cualidades o figura del padre».

Pero en este tratamiento lexicográfico discriminatorio, lo más llamativo a nuestro juicio es la riqueza sinonímica que ha proliferado tradicionalmente en el uso social de nuestro léxico para designar peyorativamente a la mujer que mantiene relaciones sexuales a cambio de dinero, y que, según la tradición cultural androcéntrica, ejerce la profesión más antigua del mundo: prostituta. Esa multiplicidad léxica y sinonímica sigue manteniéndose en el corpus del diccionario académico, pese a que muchos de esos términos aparecen con marca cronológica, antiguo («ant.») y de escaso o poco uso («p. us.») o desusado («desus.»); por tanto, su presencia y mantenimiento actual nos parecen injustificados, a pesar de las razones expuestas en la introducción de dicho diccionario que anteriormente indicamos. En cuanto al término prostituta, en las ediciones del DRAE anteriores al 2001 aparecía esta entrada sólo con género femenino y referente exclusivamente a la mujer; será a partir de la edición de ese mismo 
año, la última de este diccionario, cuando, como señal renovadora que combate el sexismo, recoge el término con flexión de género masculino y femenino: prostituto, ta: «m. y f. Persona que mantiene relaciones sexuales a cambio de dinero»; por consiguiente, aplicable tanto a hombre como a mujer. Ahora bien, en el DRAE aparecen muy diversas entradas léxicas, de las que sólo hemos tenido en cuenta las referentes al español peninsular y no las del español Atlántico, pues en ese caso las cifran serían mucho más elevadas, cuya única acepción o una de cuyas acepciones con carácter sinonímico es prostituta, en femenino; sin embargo, curiosamente, no hemos encontrado ni una sola entrada sinonímica para la forma masculina prostituto.

En total, hemos hallado 51 términos que remiten a prostituta: en una de sus acepciones, 28 de ellos; o en su única acepción, 19 en total; o bien incluyen este término en su definición, los 4 restantes. De ellos, 12 tienen flexión de género con forma masculina y femenina, y así lo consignamos, aunque las acepciones señaladas siempre están en femenino; sólo 2 tienen género masculino, y se indica; y las 37 entradas restantes y sus acepciones presentan únicamente forma morfológica femenina. En cuanto a las marcas, del total de términos encontrados 28 son términos marcados, y de ellos 3 están doblemente marcados; los 22 restantes carecen de marca alguna y, por tanto, debemos considerarlos de uso general y actual en nuestra lengua. Las marcas hacen referencia en su mayoría al registro de uso, a su poco uso e incluso desuso o a su uso regional, y también a su antigüedad.

Enumeramos a continuación estos términos, atendiendo fundamentalmente a su mayor índice de marcación, e indicamos el número correspondiente de la acepción del mismo que remite a prostituta, o bien informamos de si esa es la única acepción recogida; en cuanto al género, la mayoría de ellos tienen entrada sólo en femenino y así lo consignamos, aunque también especificamos aquéllos cuyas entradas tienen flexión de género; igualmente se indica la marcación de cada uno de ellos, en el caso de que la tengan; por último, en cuanto a su significado, lo omitimos, ya que la mayoría remiten en forma sinónímica al lema prostituta, y sólo hemos creído necesario enunciarlo en aquéllos que tienen este vocablo incluido en su definición, aunque también recogemos cualquier aclaración referente al significado incluida en la misma.

En cuanto a los términos marcados, en primer lugar, mencionamos los que tienen marca sólo de uso coloquial («coloq.»), en un total de diez términos: madama: coloq.; pelandusca: f. coloq., única acepción; peliforra: f. coloq., única acepción; pécora: mala pécora, 2. f. coloq.; pendanga: 2. coloq.; perendeca: f. coloq., única acepción; pelota: 8. con la aclaración de (porque pasa por todas las manos), f. coloq.; pecadora: flexión de género, 3. f. coloq.; pobreta: flexión de género, 3. f. coloq.; tusona: 2. f. coloq. Otros están marcados como uso despectivo («despect.»), en un total de tres términos; de ellos, uno marcado solamente como despectivo: furcia, $\mathrm{f}$. despect., única acepción; y los otros dos, doblemente marcados, como uso despectivo y coloquial: lagarta: 4. f. despect. coloq.; lagartona: flexión de género, 2. f. despect. 
coloq. Otros tres presentan marca de poco uso («p. us.»): bagasa: f. p. us., única acepción; capulina: entrada femenina, 4. p. us.; lumia: f. p. us. Y uno aparece doblemente marcado con marca de coloquial y poco uso: mozcorra f. coloq. p. us., única acepción. Igualmente tres presentan la marca de desusado («desus.»): enamorada: flexión de género, 4. f. desus.; mondaria: f. desus., única acepción; mundaria: f. desus., única acepción. Otros tres, la de uso vulgar («vulg.»): churriana: f. vulg., única acepción; pajillera: «f. vulg. Prostituta que masturbaba a sus clientes», única acepción; taxi: entrada masculina, «2. m. vulg. Prostituta que mantiene a un proxeneta». También tres con marca de registro especial de germanía («germ.»): hurgamandera: f. germ., única acepción; iza: f. germ., única acepción; marca: «11. f. germ. Prostituta, mujer pública». Otro tiene la marca cronológica de antiguo («ant.»): bordiona: f. ant., única acepción; y uno más con la marca de uso regional de Andalucía («And.»): gamberra flexión de género, 3. f. And.

El resto de los términos que enumeramos, en total veintidos, carecen de marca $\mathrm{y}$, en consecuencia, forman parte del léxico general de uso común de nuestra lengua: araña: 6. f.; buscona: flexión de género, 4. f.; cantonera: flexión de género, 5. f.; cellenca: flexión de género, 2. f.; cotorrera: 2. f.; chai: 2. f. esquinera: flexión de género, 4. f. «Prostituta que suele apostarse en las esquinas de las calles»; fulana: flexión de género, 5. f.; gabasa: f., única acepción; golfa: remite a golfo ${ }^{2}, f a, 3$. f.; gorrona: f., única acepción; hetera o su variante fonética hetaira: 2. f.; meretriz: f., única acepción; perdida: flexión de género, 5. f.; pelleja: 4. f.; perra: 2. f.; pupila: f.; puta: f., única acepción; tía: flexión de género, 13, f.; zorra: 4. f.; zorrón ${ }^{1}$ : entrada masculina, m. aum. de zorra; zorrupia: f., única acepción.

Igualmente, cabe señalar la presencia de otros términos que aluden a la relación carnal ilícita de la mujer con el hombre, como ramera: «f. Mujer cuyo oficio es la relación carnal con hombres», que, a su vez, aparece como definidor en las siguientes entradas léxicas: la primera marcada como desusado («desus.»): carcavera: sin especificación de género, «adj. desus. Se decía de la ramera que ejercía la prostitución en las cárcavas»; rabiza: «3. f. Ramera muy despreciable»; en la entrada dama, la frase dama cortesana: «f. Ramera de calidad»; y la locución una tal: (entrada en tal) «loc. sust. f. despect. Una ramera». Asimismo, el término puta, sinónimo de prostituta, aparece como sinónimo de pucha: «f. puta», única acepción. Por último, otros términos hacen referencia a la mujer que mantiene relaciones carnales fuera del matrimonio, como coima ${ }^{1}$ : «f. Concubina», única acepción; concubina: «f. Mujer que vive en concubinato»; Concubinato: «m. Relación marital de un hombre con una mujer sin estar casados», única acepción; Manceba: remite a golfo, fa: «6. f. Concubina; mantenida»: flexión de género, «6. f. Mujer que vive a expensas de un hombre con el que mantine relaciones extramatrimoniales».

Además de las entradas anteriores hay que señalar diversas locuciones y frases hechas que aluden a la mujer que comercia con su cuerpo, como: mujer del arte, del 
partido, de mala vida, del mal vivir, o de punto, y también mujer mundana, perdida, o pública, o moza de fortuna o de partido, todas ellas con el sentido sinonímico de prostituta o ramera, único sentido enfatizado sobradamente en las formas complejas del término mujer, además del de mujer fatal, que resalta el poder dañino que el atractivo femenino puede ejercer sobre el hombre y cuya definición académica y especificación de su referente no tiene, a nuestro juicio, desperdicio: «f. Aquella cuyo poder maléfico acarrea fin desgraciado a sí misma o a quienes atrae. U. referido principalmente a personajes de ficción, sobre todo de cine, y a las actrices que los representan».

Por último, también nos parece que está presente cierto tratamiento sexista en palabras que aluden profesionalmente a la mujer, a pesar de la intención académica evidente en la última edición del $D R A E$ de reflejar laboralmente la igualdad entre el hombre y la mujer, en un plausible intento de aproximarse a la realidad de los tiempos, al recoger el femenino de términos que se refieren a oficios y profesiones prestigiados socialmente y que hasta la última edición del DRAE carecían de flexión de género, como notario; o, si la tenían o la entrada aparecía en femenino, era para aludir en sus primeras acepciones a la condición de mujer de la persona designada por el masculino, como alcaldesa, coronela, gobernadora, presidenta, etc., aunque aún quedan algunas entradas referentes a profesiones ejercidas tanto por la mujer como por el hombre que carecen de flexión de género, entre otros, juez, magistrado o cónsul.

En cuanto a otros términos que se refieren profesionalmente a la mujer, abundan los que aluden al desempeño de trabajos domésticos. De ellos, algunos siguen teniendo plena vitalidad de uso en nuestra sociedad actual y, en consecuencia, su presencia en el DRAE está justificada, como ama: «6. f. Criada principal de una casa»; asistenta: «f. Mujer que sirve en una casa sin residir en ella»; chica: «10. f. Criada que trabaja en los menesteres caseros»; doncella: «2. f. Criada que sirve cerca de la señora y se ocupa de los menesteres domésticos ajenos a la cocina»; interina: «3. f. Sirvienta en una casa particular que no pernocta en ella»; niñera: «2. f. Criada destinada a cuidar niños»; sirvienta: «f. Mujer dedicada al servicio doméstico». Sin embargo, hay otros que, si bien en el pasado designaron una realidad existente y, en consecuencia, su uso era general y aceptado socialmente, hoy, en nuestra sociedad actual, carecen de referente, al haber desaparecido esa realidad y, por tanto, también su uso; a pesar de ello, siguen presentes en el diccionario sin marca cronológica ni de uso, como asistenta: «5. f. Criada que servía en el palacio real a damas, señoras de honor y camaristas que habitaban en él»; camarista: «3. f. Criada distinguida de la reina, princesas o infantas»; escucha: «4. f. Criada que dormía cerca de la habitación de su ama para poder oír si la llamaba»; guardamujer: «f. Criada de la reina que acompañaba en el coche a las damas»; además de algunas frases hechas con un claro uso arcaico, como moza de cámara: «f. La que servía en los oficios de la casa en grado menor de doncella»; y moza de cántaro: «f. Criada que se tenía en la casa con la obligación de traer agua y de ocuparse en las tareas domésticas». Asimismo, se recogen otros términos 
referentes a la mujer que desempeña tareas domésticas, que implican un trato profesional denigrante para ésta: bien sin marca, como moza: «11. f. Criada que sirve en menesteres humildes y de tráfago»; bien marcados como uso coloquial, como chacha: «3. f. coloq. Niñera», y «4. f. coloq. Sirvienta»; bien con doble marcación, de uso coloquial y poco usado, como menegilda: «f. colq. y p.us. Criada de servicio»; o marcados como uso despectivo y coloquial, como marmota: «4. f. despect. coloq. Mujer empleada en el servicio doméstico»; o bien marcados como uso despectivo y poco usado, como mondonga: «f. despect. p. us. Criada zafia».

Como hemos podido observar en este rápido recorrido lexicográfico, en el $D R A E$ se siguen manteniendo, a nuestro juicio de forma injustificada, usos léxicos referentes a modelos sociales femeninos ya caducos, cuyas definiciones transmiten a los usuarios de este diccionario una imagen cultural de la mujer sesgada, distorsionada y en muchas ocasiones envilecida, así como unos valores culturales discriminatorios y sexistas. Por ello, y para concluir, insistimos en la necesidad de revisar el corpus del diccionario académico y su discurso definidor, con el fin de adecuarlo a la realidad de nuestra lengua y cultura, pues, en una sociedad transformada, que defiende el igualitarismo social, la presencia en sus páginas de esos usos léxicos que entrañan discriminación de género ya no tiene ningún sentido.

\section{REFERENCIAS BIBLIOGRÁFICAS}

Alvar Ezquerra, M. (1981): «Los diccionarios bilingües: su contenido», Lingüística española actual, $\mathrm{III} / 1$, pp. 175-196.

— (1993): «La lexicología en los últimos veinte años», en Lexicografía descriptiva, Barcelona, Biblograf, pp. 13-38.

Calero, $M^{a}$. A (1999): «Diccionario, pensamiento colectivo e ideología (o los peligros de definir)», en M. N. Vila y otros, eds., Así son los diccionarios, Lleida, Universidad de Lleida, pp. 149- 201.

Catalá, A. y E. García Pascual (1995): Ideología sexista y lenguaje, Barcelona, Octaedro.

DRAE-2001. Real Academia Española (2001): Diccionario de la lengua española, Madrid, EspasaCalpe.

Dubors, J. (1971) : «Dictionnaire et discours didactique», Langages, 19, pp. 236-249.

Forgas, E. (1996): «Lengua, sociedad y diccionario: la ideología», en E. Forgas, coord., Léxico y diccionarios, Tarragona, Universitat Rovira i Virgili, pp. 71-89.

García Meseguer, A. (1988): Lenguaje y discriminación sexual, Barcelona, Montesinos. 
Grijelmo, A. (2000): «La desaparición de la mujer», en La seducción de las palabras, Madrid, Taurus, pp. 243-256.

Lara, L. F. (1997): Teoría del diccionario monolingüe, México, Colegio de México.

Pascual, J. A. y M M C. Olaguíbel (1991): «Diccionario e ideología», en I. Ahumada, ed., Diccionarios españoles: contenidos y aplicaciones, Jaén, Universidad de Jaén, pp. 73-89.

Rey-Debove, J. (1971): Étude linguistique et sémiotique des dictionnaires français contemporains, La Haya-París, Mouton. 